\title{
Effects of a management technician on structured working in Dutch community pharmacies
}

- Miranda C.M. Pronk, Lyda Th.G. Blom, Ruud Jonkers and Albert Bakker

Pharm World Sci 2004; 26: 221-226.

(c) 2004 Kluwer Academic Publishers. Printed in the Netherlands.

M.C.M. Pronk (correspondence, e-mail:

mcmpronk@zonnet.nl), L.Th.G. Blom, A. Bakker: Department of Pharmacoepidemiology and Pharmacotherapy, Utrecht Institute for Pharmaceutical Sciences (UIPS), PO Box 80082,

3508 TB Utrecht, The Netherlands

R. Jonkers: ResCon, Haarlem, The Netherlands

Key words

Community pharmacy

Community pharmacy services

Patient education

Pharmacy organisation

Pharmacy technicians

The Netherlands

\section{Abstract}

Objective: To study the effects of 'stepwise working with the help of a management technician' on structured working with regard to patient education in a sample of Dutch community pharmacies

Methods: The intervention program provided the management technician with knowledge, tools and skills needed for the organisation of patient education activities in her community pharmacy. Twenty-eight pharmacies were selected for the study. After matching, each pharmacy was randomly assigned to either the experimental or control group. In the pharmacies of the experimental group, a technician was selected to become the management technician.

Main outcome measures: Pharmacy technicians were assessed

by means of written questionnaires at baseline and

immediately after the intervention (12 months). The outcomes were the variables that were directly targeted by the

intervention, and included technicians' perception of the availability of policy plans, support for patient education activities towards their implementation, evaluation, and provisions for continuity.

Results: After 12 months, the following indicators for structured working were noted to have increased in the experimental group compared to the control group: the technicians in the experimental group more often reported an awareness of policy plans, less lack of continuity of activities, support and evaluation for implementing patient education activities. We also observed that the control group had a higher baseline level and the effects on support and evaluation showed differences between pharmacies. The observed increases were more pronounced in pharmacies that had a higher exposure to the intervention, and in the case of support and evaluation relevant in this more exposed group. Conclusion: We found indications for effects of the intervention program, especially in the pharmacies with increased exposure. However, results could be influenced by regression to the mean, as the control group started with a higher mean than the experimental group. We conclude that technicians' participation in the management of patient education activities appears to be effective when she has a minimum of hours to spend on this task in her pharmacy.

Accepted October 2003

\section{Introduction}

Dutch community pharmacies have been directing their attention more and more towards patient-oriented activities. The communication with patients has become increasingly important. Still, structured patient education is not carried out as a routine task ${ }^{1,2}$. Mobach ${ }^{3}$ observed that the product-oriented practice conception is still very much present in Dutch community pharmacies, although pharmacists want to change towards more patient education. The imple- mentation of patient education activities is often seen as a problem ${ }^{4-6}$. Barriers with regard to the implementation of patient education seem to be related mainly to the organisation of patient education activities ${ }^{7}$. Farris and Schopflocher ${ }^{8}$ concluded that adjusting the environment to implement pharmaceutical care is important. In addition, Holland and Nimmo 9,10 have proposed 'a systems view' of pharmacy practice - the total pharmacy care model - which should lead to the delivery of a comprehensive range of pharmaceutical care services. Garside ${ }^{11}$ stated that to manage an innovation process effectively, one should pay attention to several important organisational aspects, mainly related to project management. She recommended to appoint a project team, show early and mid-term successes to maintain motivation and provide enough time.

This paper reports on the effects of a theory- and practice-based intervention that was developed after a thorough needs assessment. As such, it is part of a larger intervention development and evaluation study ${ }^{12}$. With our intervention, the aim was to facilitate a change in the work processes towards structured working with regard to patient education. Therefore an intervention was developed that taught the management technicians about stepwise working on patient education in their pharmacy. One pharmacy technician of every pharmacy received training to become the management technician in her pharmacy. Their training took place on two levels to realise the stepwise development of patient education activities. Firstly, at the course technicians were provided with knowledge, tools and skills and secondly, they had to apply this expertise to workplace tasks in the pharmacy (Figure 1).

The objective of this study was to assess the effect of the intervention program on structured working. The intervention program is described in Table 1. Structured working was operationalised as different elements and activities, which were chosen as indicators for the implementation of structured working in pharmacies:

- Whether the pharmacy has a policy plan that includes plans for patient education activities;

- Support for technicians for the execution of the activities, by means of somebody to communicate with about patient education, clear agreements about patient education, and availability of patient education materials;

- Evaluation of patient education activities in staff meetings;

- Feedback by the management technician, pharmacist, and colleagues on the patient education activities that were carried out. 
$1^{\text {st }}$ level $\quad 2^{\text {nd }}$ level

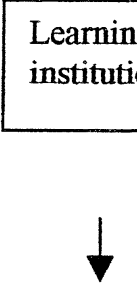

Course:

Knowledge

Skills

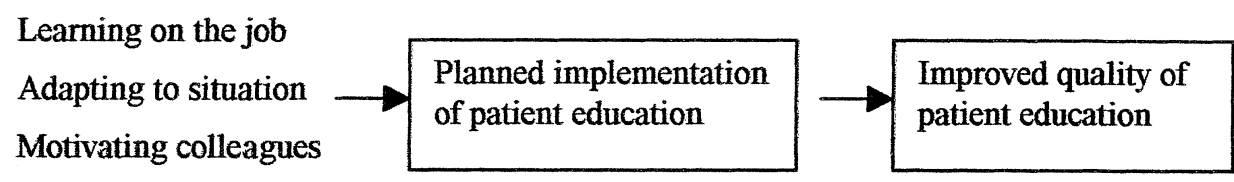

Figure 1 Two levels of education and their expected effects.

Methods

\section{Research design}

The effects of the intervention study were evaluated comparing pre-intervention and post intervention measurements and experimental and control groups. The experimental group received the intervention program (described in the introduction) from March 1999 to January 2000, while the control group received no intervention. A baseline survey (T0) was carried out in both groups one month before the start of the intervention. A post-intervention survey (T1) was done in the month following the completion of the intervention.

\begin{abstract}
Sample
We took a sample from Dutch pharmacies that were developing patient education activities but were experiencing difficulties with their implementation. The selection criteria were based on theory and on preliminary research ${ }^{2,7}$. The size of the sample was limited by the number of pharmacies that could be entered into the course, which was 14 . This resulted in a procedure in which 28 pharmacies were included, matched in pairs of similar pharmacies and randomly assigned to either the experimental or the control group. The matching criteria referred to conditions that might influence the effect of the intervention, including the nature of the problem with regard to patient education (no patient education when the pharmacy is busy, lack
\end{abstract}

Table 1 The intervention program and tasks that were defined for management technician and pharmacist

The intervention program consisted of eight course meetings for technicians and four course meetings for pharmacists, spread over one year. One technician and one pharmacist of every pharmacy took part. Based on theory, literature, and field study, tasks were defined for the technician who took part in the course and who had to increase and promote structured working in her pharmacy. In addition, tasks for the pharmacist were defined, because he had to guide, support and coach the activities of the management technician. The tasks were learned and applied step-by-step in the pharmacies, starting with an assessment of the current situation. The next steps were making plans for change, the execution of these plans and the evaluation and anchoring of the new activities. The intervention program was carried out by a specialised organisation (Netherlands Institute for Health Promotion and Disease Prevention, NIGZ). The researchers made observations of the course meetings.

Tasks management technician

- Observe bottlenecks and needs of technicians and patients with regard to patient education;

- Take initiatives to solve the problems with regard to practising patient education;

- Evaluate whether the chosen solutions work;

- Observe educational needs of colleagues and put them through to the pharmacist;

- Take care of a patient leaflet management system ${ }^{\mathrm{a}}$;

- Be the person to talk to with regard to patient education for colleagues;

- Be the person to talk to with regard to patient education for the pharmacist.
Tasks pharmacist

- Take care of the guidance of the work process regarding improvement of the quality of patient education and communication in the pharmacy;

- Delegate tasks to the management technician;

- Develop a policy with regard to changing the work process around patient education in the pharmacy.

a A leaflet management system includes all the organisational activities with regard to leaflets: the decisions and agreements about which leaflets are used when and where (at the counter, in a leaflet holder) the logistics (availability of leaflets), etc. 
of clear agreements on patient education, lack of continuity of activities, and using knowledge and skills learned in courses is a problem), the presence of delegation of tasks from pharmacist to technicians (delegation of patient education tasks, delegation of other tasks, no delegation of tasks), the size of the pharmacy, and the type of computer system.

\section{Data collection}

To evaluate the effects of the intervention program, questionnaires were sent to all pharmacy technicians, except the management technicians in the experimental group. The questionnaires were returned to the researchers free of charge by each individual technician.

\section{Exposure to the intervention}

The level of exposure of pharmacies and pharmacy technicians to the intervention was determined by telephone interviews of the pharmacists and management technicians. Management technicians also kept diaries of the activities they carried out. These data are not fully elaborated in this paper. The interviews and diaries identified the steps of structured working that were carried out in the pharmacy, along with the facilitating and hindering factors with regard to carrying out management technician's tasks. The diaries were also used to collect data about the total time spent by the management technicians on their management tasks. These data were used to select the pharmacies based on their exposure to the intervention, in order to determine whether the level of exposure had influenced the results.

\section{Data analysis}

The technician's surveys collected at T0 and T1 were merged into one file. Statistical analyses were done using SPSS, version 10.0. The internal consistency of groups of theoretically similar questions was tested. Groups of questions that showed a minimum value of 0.65 for Crohnbach's alpha were considered a cluster. These clusters are shown in Table 2.
The effects were assessed by a comparison of $\mathrm{T} 1$ against T0 (the change, $\Delta[\mathrm{T} 1-\mathrm{T} 0]$ ) on the outcome variables of the technicians of the experimental and control group. For this purpose, a nested repeated measurement Analysis of Variance (nested RMANOVA) was applied. This test takes into account both the repeated measures (T0 - T1) within subjects (technicians) and the differences between groups of subjects (pharmacies). In addition, the technicians from the experimental group were studied in more detail with a similar nested RM-ANOVA with $\Delta(\mathrm{T} 1-\mathrm{T} 0)$ as within subjects' effects and pharmacies as between subjects' factors. This analysis was done because the earlier nested analysis including the control groups did not give specific information as to where differences are found, making interpretation difficult. By doing nested RM-ANOVAs, baseline differences between pharmacies were taken into account. In addition, the nested RM-ANOVA can reveal a statistically significant interaction effect between the outcome measure and pharmacies. This variability would be explained by differences between pharmacies.

For ordinal variables, the Mann-Whitney test was employed as test of the mean $\Delta(\mathrm{T} 1-\mathrm{T} 0)$ between experimental and control groups. The Wilcoxon Signed Ranks test was used to test $\Delta(\mathrm{T} 1-\mathrm{T} 0)$ for each group of technicians. Ninety-five percent confidence intervals were estimated and cases with missing values were excluded. In addition, these analyses were carried out with selections of the technicians of the more exposed pharmacies.

\section{Results}

\section{Exposure to the intervention and barriers}

The management technicians attended nearly $100 \%$ of the course meetings. Although every pharmacy reached the fourth step in the planning model ('making a plan for change'), not every pharmacy had carried out this plan at T1. Pharmacies that carried out their plans at T1 were included in additional analyses.

\section{Table 2 Clusters of questions used for the effect analyses}

Support for practicing patient education activities (Crohnbach's alpha 0.73)

1. I know whom I should ask for help on a subject that I do not know very much about;

2. The help that I get when I have problems with patient education solves the problem;

3. As a team, we are working well together to improve the patient education in the pharmacy;

4. There is somebody in our pharmacy who supervises whether everybody succeeds in following the agreements that we made about patient education;

5. There is somebody in our pharmacy who supervises that the planning of patient education activities and projects is running correctly;

6. There is somebody in our pharmacy who looks after educational needs of colleagues.

Answering categories [always-most of the time-sometimes-seldom-never]

Evaluation of patient education activities (Crohnbach's alpha 0.91)

7. In our staff meetings we talk about how new patient education activities are being carried out;

8. In our staff meetings we try to find out whether problems exist with the execution of the activities;

9. In our staff meetings we agree on how we proceed with new patient education activities.

Answering categories [always-most of the time-sometimes-seldom-never] 


\begin{tabular}{|c|c|c|c|c|}
\hline & \multicolumn{2}{|c|}{$\operatorname{Exp}(\mathrm{n}=75)$} & \multicolumn{2}{|c|}{$C t I(n=73)$} \\
\hline & Mean & $(s d)$ & Mean & $(s d)$ \\
\hline Age (years) & 31.9 & $(9.1)$ & 34.5 & $(8.9)$ \\
\hline Women (\%) & 99 & & 100 & \\
\hline Years of experience & 10.1 & $(6.8)$ & 12.1 & $(7.8)$ \\
\hline Years of experience in this pharmacy & 6.8 & $(5.4)$ & 7.5 & $(5.8)$ \\
\hline Number of hours per week & 28.2 & $(9.0)$ & 26.6 & $(8.2)$ \\
\hline Patient education in professional education (\% of respondents) & 31 & & 26 & \\
\hline Number of communication courses attended/last three years & 0.9 & $(0.9)$ & 1.4 & $(1.1)$ \\
\hline Number of medicines courses attended/last three years & 3.1 & $(2.6)$ & 2.8 & $(2.2)$ \\
\hline
\end{tabular}

Another point of interest was the time spent by management technicians on their management activities. The recommended total time was 188 hours, which equals 4 hours per week. However, the total hours reported ranged from 1 to 80 . Reasons that were given for not spending the recommended time included a general shortage of time in the pharmacy, related to illness, absence of colleagues, or work pressure. The criterion of a minimum of 40 hours spent on management technician activities was used to select the more exposed pharmacies.

Based on these two conditions (plans carried out and $>40$ hours spent), the respondents of 6 pharmacies of the experimental group were selected for additional analyses.

\section{Respondents}

At T0, questionnaires were distributed among the 145 technicians of the experimental group, of which 130 (84\%) were returned. Of the questionnaires that were distributed among the 121 technicians in the control group, 106 (88\%) were returned. After the course had ended, at $\mathrm{T} 1$, the same number of questionnaires was distributed, with exclusion of the 14 management technicians in the experimental group. A total of 89 questionnaires of the 131 (68\%) questionnaires were returned in the experimental, while in the control group 117 questionnaires (96\%) were returned. Only the technicians that provide data at T0 and T1 were used for assessing the effects (experimental group $n=75$; control group $n=73$ ). These effects could be studied with the data of the pharmacy technicians of 12 out of 14 pharmacies, with 2 pharmacies dropping out of the study. The reasons for management technicians dropping out were long-term illness in one pharmacy and the reported inability to cope with the new role for various reasons (lack of experience in their pharmacy, lack of support from the pharmacist, or lack of time to carry out her tasks) in the other pharmacy.

The background characteristics of the technicians of the pharmacies that were included in the study are shown in Table 3, and demonstrate the comparability of the experimental and control group.

\section{Effects}

The effects of the intervention were studied by analysing the differences of technicians' perceptions between T0 and T1 of the following indicators: policy plans, policy plans with regard to patient education, continuity of activities, support for developing and carrying out patient education activities, and evaluation of patient education activities.

The number of positive answers to the question 'Does your pharmacy have a policy plan?' increased statistically significant in the experimental group at T1 (T0: $24 \%, \mathrm{~T} 1: 48 \% ; P<0.05)$ but not in the control group (Table 4$). \Delta(\mathrm{T} 1-\mathrm{T} 0)$ of the experimental group was different from $\Delta(\mathrm{T} 1-\mathrm{T} 0)$ of the control group (Mann-Whitney test, $P=0.003$ ). Note that the control group had a higher baseline level. With regard to the second question ('Are plans for patient education included in the policy plan'), no changes were observed. One question reflected the perceived lack of continuity of patient education activities: 'We start patient education activities very enthusiastically, but this enthusiasm subsides quickly'. The answers showed a statistically significant $\Delta(\mathrm{T} 1-\mathrm{T} 0)$ in both the experimental (T0: 2.89 (0.62), T1 $3.07(0.65), P=0.02)$ and the control group (T0: 3.25 (0.71), T1: 2.97 (0.77), $P=0.006)$. The experimental group was found to retain their enthusiasm more successfully than the control group (Mann-Whitney test, $P=0.001$ ), but the control group started with a higher mean. In addition, the Mann-Whitney test was carried out with the respondents of the selection that was described earlier ('Exposure to the intervention and barriers'). This selection showed a statistically significant increase at T1 (T0: 2.95 (0.60), T1 3.40 (0.50), $P=0.007)$.

With regard to the results for 'Support for practising patient education activities' (see questions in Table 2), a statistically significant $\Delta(\mathrm{T} 1-\mathrm{T} 0)$ was found with the overall nested RM-ANOVA $(F(1,110)=6.752$, $P=0.011)$. The interaction factor of pharmacies with 'Support' was statistically significant as well $(F(22,110)$ $=2.793, P<0.001)$. A nested RM-ANOVA with only the experimental group revealed a statistically significant increase of 'Support' $(F(1,57)=15.641, P<$ $0.001)$ and an interaction of pharmacy with 'Support' $(F(11,57)=3.546, P=0.01$; Table 5$)$. The analysis with the respondents of the more exposed pharmacies revealed a statistically significant increase of 'Support' $(F(1,31)=29.734, P<0.001)$.

Tested with the nested RM-ANOVA, 'Evaluation of patient education activities' increased statistically significant $(F(1,121)=16.102, P=0.010)$ in the experimental group in comparison with the control group. When a nested RM-ANOVA was carried out with the data of the experimental group (Table 5), a statistically significant interaction between pharmacies and this variable was found $(F(11,61)=4.058, P<0.001)$. It 


\begin{tabular}{|c|c|c|c|c|c|c|}
\hline & & $\begin{array}{l}\text { Exp } \\
\% \text { 'yes' }\end{array}$ & $\begin{array}{l}\text { Wilcoxon } \\
\text { P-value } \\
\text { (n) }\end{array}$ & $\begin{array}{l}\text { Ctl } \\
\% \text { 'yes' }\end{array}$ & $\begin{array}{l}\text { Wilcoxon } \\
\text { (n) }\end{array}$ & $\begin{array}{l}\text { Mann- } \\
\text { Whitney } \\
\text { P-value }\end{array}$ \\
\hline Does your pharmacy & T0 & 24 & & 56 & & \\
\hline $\begin{array}{l}\text { have a policy plan? } \\
(0-1)\end{array}$ & $\mathrm{T} 1$ & 48 & $0.003^{d}(75)$ & 53 & $0.257(73)$ & $0.003^{c}$ \\
\hline \multirow[t]{2}{*}{ Selection of pharmacies ${ }^{a}$} & TO & 22 & & 41 & & \\
\hline & $T 1$ & 59 & $0.001^{d}(41)$ & 31 & $0.317^{d}(29)$ & $0.002^{c}$ \\
\hline \multirow{3}{*}{$\begin{array}{l}\text { Are plans for patient } \\
\text { education included in } \\
\text { the policy plan? }(0-1)\end{array}$} & T0 & 33 & & 58 & & \\
\hline & T1 & 43 & $0.132(75)$ & 47 & $0.527(73)$ & 0.318 \\
\hline & & $\operatorname{Mean}^{b}(s d)$ & $\begin{array}{l}\text { Wilcoxon } \\
\text { (n) }\end{array}$ & $\operatorname{Mean}^{b}(s d)$ & $\begin{array}{l}\text { Wilcoxon } \\
(\mathrm{n})\end{array}$ & $\begin{array}{l}\text { Mann- } \\
\text { Whitney }\end{array}$ \\
\hline \multirow{4}{*}{$\begin{array}{l}\text { We start very enthusias- } \\
\text { tically with patient edu- } \\
\text { cation activities, but } \\
\text { they subside quickly } \\
\text { (continuity) (1-5) } \\
\text { Selection of pharmacies }\end{array}$} & T0 & $2.89(0.62)$ & & $3.35(0.71)$ & & \\
\hline & T1 & $3.07(0.65)$ & $0.020^{d}(71)$ & $2.97(0.77)$ & $0.006^{d}(70)$ & $0.001^{c}$ \\
\hline & TO & $2.95(0.60)$ & & $3.06(0.68)$ & & \\
\hline & $T 1$ & $3.40(0.50)$ & $0.007^{d}(20)$ & $2.60(0.74)$ & $0.035^{\mathrm{d}}(15)$ & $0.001^{c}$ \\
\hline
\end{tabular}

\footnotetext{
a Six 'experimental' pharmacies and their six matches in the control group (twelve pharmacies). Selections based on process evaluation: 'carried out plans' in the stepwise model and the management technician spent in total $>40$ hours on her tasks.

${ }^{\mathrm{b}} \mathrm{A}$ higher value is more positive, for example: a higher value means the activities subside less quickly.

c Statistically significant $(P<0.05)$ difference between experimental and control group, tested with Mann-Whitney test.

d Statistically significant $(P<0.05)$ change between T0 and T1, tested with Wilcoxon signed ranks test.
}

increased statistically significant in the selection of technicians of more exposed pharmacies $(F(1,35)=17.190, P<0.001)$.

\section{Discussion}

Some may think that our design does not allow for detailed analyses, but for descriptive analyses only. How- ever, we felt that a somewhat detailed analysis as presented here was feasible and justified.

Often in intervention studies the actual implementation of the intervention is not studied in detail. In this study the process evaluation was specifically emphasized, because offering an intervention does not always mean that is implemented according to plan. It appeared that our intervention was not implemented

Table 5 Effects on interval/ratio-level outcomes (nested RM-ANOVA)

\begin{tabular}{|c|c|c|c|c|c|c|c|}
\hline & & \multicolumn{2}{|l|}{$\operatorname{Exp}$} & \multirow{2}{*}{$\begin{array}{l}\text { P-value } \\
\text { main within subj. } \\
\text { effect }(\mathrm{n})\end{array}$} & \multicolumn{2}{|l|}{$C t$} & \multirow{2}{*}{$\begin{array}{l}\text { P-value main } \\
\text { within subj. effect } \\
\text { (n) }\end{array}$} \\
\hline & & Mean & $(s d)$ & & Mean & $(s d)$ & \\
\hline \multirow{4}{*}{$\begin{array}{l}\text { Support for pa- } \\
\text { tient education } \\
\text { activities (6-30) } \\
\text { Selection of phar- } \\
\text { macies }^{a}\end{array}$} & T0 & 19.56 & $(4.34)$ & & 20.45 & (3.53) & \\
\hline & $\mathrm{T} 1$ & 21.64 & $(4.18)$ & $0.000(69)^{b c}$ & 20.38 & $(4.01)$ & $0.602(65)$ \\
\hline & TO & 18.95 & $(4.81)$ & & 19.12 & $(3.22)$ & \\
\hline & $T 1$ & 22.43 & (3.95) & $0.000(37)^{\mathrm{b}}$ & 18.69 & $(3.60)$ & $0.197(26)$ \\
\hline \multirow{2}{*}{$\begin{array}{l}\text { Evaluation of pa- } \\
\text { tient education } \\
\text { activities (3-15) }\end{array}$} & T0 & 9.70 & $(2.80)$ & & 10.22 & $(2.23)$ & \\
\hline & $\mathrm{T} 1$ & 9.91 & $(2.18)$ & $0.737(73)^{c}$ & 9.38 & $(2.50)$ & $0.000(72)^{b}$ \\
\hline \multirow{2}{*}{$\begin{array}{l}\text { Selection of phar- } \\
\text { macies }^{\text {a }}\end{array}$} & TO & 9.07 & (3.09) & & 9.50 & $(2.78)$ & \\
\hline & $T 1$ & 10.56 & (1.95) & $0.000(41)^{b}$ & 8.04 & $(2.74)$ & $0.006(28)^{b}$ \\
\hline
\end{tabular}

\footnotetext{
a Six 'experimental' pharmacies and their six matches in the control group (twelve pharmacies). Selections based on process evaluation: 'carried out plans' in the stepwise model and the management technician spent in total > 40 hours on her tasks (for protocols extra selections were made of the pharmacies that reported working on OTC, first Rx or second Rx protocols).

b Nested RM-ANOVA (experimental and control group separately): within subjects factor T0-T1 statistically significant; $P<0.05$.

c Nested RM-ANOVA (experimental and control group separately): interaction effect '(T0-T1)*pharmacy' statistically significant: $P<0.05$.
} 
as it was supposed to by every participating pharmacy. Although the attendance rates to the course meetings were high, the management technicians spent on average much less time than planned on their management tasks in their pharmacies. The selections of more exposed pharmacies showed more pronounced effects, which indicates that the extent to which the intervention was implemented by the pharmacies has influenced the results.

The effects of the intervention were studied in a field study with an experimental and a control group of pharmacies. Although the pharmacies were matched and appeared to be alike with regard to mean background variables, the results showed that the control group scored higher on the outcome variables at baseline. This limits the strength of the effects that were found in the experimental group, because these could also be caused by regression to the mean. In addition, the nested design of the study made it necessary to do a nested analysis. For this purpose a nested repeated measures analysis of variance was applied.

This study showed that in studies like these it is almost inevitable to have a complicated research design. This is caused by the differences that exist between pharmacies. Future research that aims at increasing structured working or the implementation of patient education activities should take these differences into account. More research is necessary on ways to deal effectively with those differences in research, both with regard to the study designs and the methods of analysis. And a proper evaluation of the exposure to the intervention, and its implementation in pharmacy practice should be examined thoroughly, to be able to adjust the results to the exposure. In addition, more research is recommended on each step of the development and execution of patient education activities in community pharmacies and the relations between these steps.

The results of this study demonstrate the effects of an intervention on structured working at patient education, limited by the extent to which the intervention was implemented. An increase was observed in the percentage of policy plans. As the control group started with a higher percentage that decreased, the increase can be explained by regression to the mean. With regard to 'Support' and 'Evaluation', mixed effects were found. This means that effects were not the same for every pharmacy. The selection of more exposed pharmacies confirms the conclusion that a higher exposure leads to increased results with regard to these outcome measures. In the selection, the increase in 'Support', 'Evaluation' and 'Continuity of patient education activities' was stronger. This indicates that the intervention promises to contribute to the increase of structured working with regard to patient education. However, proper implementation of the intervention is an important precondition.

Although 'enough time' (at least four hours a week) was required for entry into the study and at the start of the intervention period the pharmacists indicated that this was possible, not every pharmacy succeeded in complying with this precondition. This is an explanation for the limited amount of effect found, because the amount of time the management technician spent on her tasks is likely to be a predictor of the effects of her tasks ${ }^{13}$. The main reasons given for lack of time were related to a shortage of technicians. The general shortage of technicians is a problem that is currently recognised in the Netherlands ${ }^{14}$. This barrier was also recognised by Garside ${ }^{11}$.

\section{Conclusion}

As it appears now, a pharmacist may delegate the management of patient education activities, as we found that a pharmacy technician is able to work as a patient education manager. This specialisation fits into the current evaluation of job differentiation and appreciation $^{15}$.

Our findings suggest that even the innovative pharmacies need more time to change towards customeroriented activities.

\section{Acknowledgements}

The authors want to express their thanks to the pharmacists, management technicians and pharmacy technicians of the participating pharmacies for their co-operation in conducting this study.

\section{Funding}

This study was supported financially by SBA and SALapotheken.

\section{References}

1 Van Mil FJW, Tromp DF, McElnay JC et al. Development of pharmaceutical care in The Netherlands: pharmacy's contemporary focus on the patient. I Am Pharm Assoc 1999; 39: 395-401.

2 Pronk M, Blom L, Jonkers R, Bakker A. Community pharmacy and patient-oriented activities: the Dutch case. Patient Edu Couns 2002; 46: 39-45.

3 Mobach M. Thought and Action. Change to the Customer in Community Pharmacy Practice. Groningen: Rijksuniversiteit Groningen 1999.

4 Osman L, Bond CM, Mackenzie J, Williams S. Asthma advice giving by community pharmacists. Int J Pharm Pract 1999; 7: 12-7.

5 Narhi $U$, Airaksinen $M$, Enlund $H$. Do asthma patients receive sufficient information to monitor their disease - a nationwide survey in Finland. Pharm World Sci 2001; 23: 242-5.

6 Van Mil JFW. Pharmaceutical Care, the Future of Pharmacy. Theory, Research and Practice. Groningen, The Netherlands: Rijksuniversiteit Groningen 2000. ISBN 90-9013367-4.

7 Pronk MCM, Blom AThG, Jonkers R,Van Burg A. The diffusion process of patient education in Dutch community pharmacy: an exploration. Patient Edu Couns 2001; 42: 115-121.

8 Farris K, Schopflocher DP. Between intention and behavior: an application of community pharmacists' assessment of pharmaceutical care. Soc Sci Med 1999; 49: 55-66.

9 Holland RW, Nimmo CM. Transitions in pharmacy practice, part 3: effecting change - the three-ring circus. Am J Health Syst Pharm 1999; 56: 2235-41.

10 Holland RW, Nimmo CM. Transitions, part 1: beyond pharmaceutical care. Am J Health Syst Pharm 1999; 56: 1758-64.

11 Garside P. Organisational context for quality: lessons from the fields of organisational development and change management. Qual Health Care 1998; 7: S8-S15.

12 Pronk MCM. Implementation of patient education in Dutch community pharmacies; development and evaluation of a new strategy. Utrecht, The Netherlands: University of Utrecht 2002.

13 Rogers EM. Diffusion of Innovations. 4th edition New York: The Free Press 1995.

14 Stichting Farmaceutische Kengetallen. Farmacie in cijfers. Hoge werkdruk in apotheken [Pharmacy in figures. High workload in pharmacies.] Pharm Weekbl 2002; 137: 637.

15 KNMP. Hoofdbestuur geeft visie op functiewaardering in de apotheek [The management board give their vision on job appreciation in the pharmacy.] Pharm Weekbl 2002; 137: 781. 